\title{
PANELLUS STYPTICUS: GEOGRAPHICALLY SEPARATED INTERBREEDING POPULATIONS
}

\author{
Ronald H. PETERSEN ${ }^{1}$ \\ Botany Department, University of Tennessee, Knoxville, Tennessee 37916 \\ AND \\ DAVID BERMUDES \\ University of Wisconsin-Milwaukee, Center for Great Lakes Studies, \\ Milwaukee, Wisconsin 53204
}

\begin{abstract}
Utilizing matings of single-spore isolates of collections of Panellus stypticus from far eastern USSR, New Zealand, Japan and eastern North America, the geographic range of interbreeding populations was ascertained to include all these locations. Culture bioluminescence and basidiome taste differed across this range, apparently independent of sexual compatibility.

Key Words: bioluminescence, geographical distribution, Japan, mating systems, New Zealand, species concept, United States, USSR
\end{abstract}

Panellus stypticus (Bull. \& Vent. : Fr.) Karsten (Agaricales, Tricholomataceae) is well-known over the North Temperate Zone and has been reported from southeastern Australia by Reid (1955) and New Zealand by Segedin (1987).

Previous papers on the mating system of $P$. stypticus (Macrae, 1937, 1942; Petersen and Bermudes, 1991) have reported the species to be bifactorial (= tetrapolar). Others (O'Kane et al., 1990a, b; Bermudes et al., 1990) have described various aspects of bioluminescence in the species from eastern North America. Macrae (1937) had already noted that "Eurasian" isolates were not bioluminescent (although she offered data only on European isolates). Her report also implied that interbreeding populations of $P$. stypticus extended from eastern North America to Europe, even though biochemical characters (bioluminescence) differed. Petersen and Bermudes (1991) reported that Japanese isolates, while universally intercompatible with isolates from eastern North America, also were not bioluminescent, and that single-spore isolates from eastern North America also commonly lacked bioluminescence.

The present paper is intended to report a further extension of the range of interbreeding to eastern Soviet Union and New Zealand, to provide information on distribution of biolumines-

\footnotetext{
${ }^{1}$ Corresponding author.
}

cence and basidiome taste, and to discuss the implication of these data in the context of species concepts.

\section{MATERIALS AND METHODS}

Specimens utilized. -JAPAN. Tochigi Pref., vic. Lake Chuzenjiko, 27.IX.89, RHP 2315(TENN 48762). NEW ZEALAND. North Island: Urewera Nat. Park, 29.V.90, coll. RHP \& K. W. Hughes, on Nothofagus, RHP 2810 (TENN 48775); South Island: Canterbury, vic. Lewis Pass, St. James Nature Walk, 12.V.90, on Nothofagus, RHP 2586 (TENN 48831); Fiordland, Monowai, Borland Lodge Track, 19.V.90, on Nothofagus, RHP 2664 (TENN 48830); same location and date, RHP 2675 (TENN 48833); Fiordland, Te Anau, Lower Keplar Track, 18.V.90, on Nothofagus, RHP 2658 (TENN 48837). RUSSIA. Terr. Primorsk: Sichote Alin Biosphere Preserve; Vasnaya, 9.IX.90, on ?Betula, RHP 3180 (TENN 48834); Kabanya, 14.IX.90, on hardwood log, RHP 3281 (TENN 48832); Blagodotnoya, 22.IX.90, on Quercus, RHP 3342 (TENN 48835); same location and date, RHP 3350 (TENN 48836). UNITEDSTATES. TENNESSEE: Great Smoky Mountains National Park, Bullhead Trailhead, 19.I.90, on hardwood log, RHP 2536 (TENN 48764).

Methods. - Detailed methods can be obtained from the paper by Petersen and Bermudes (1991). Briefly, singlespore isolates were obtained by harvesting basidiospore germlings on malt extract agar. Colonies from these germlings were self-crossed in all combinations to ascertain the mating system of each collection. Tester strains for each mating type were designated and subsequently mated with tester strains from other collections from within the geographic area, and then with 
tester strains from other areas. Formation of clamp connections was used as presumptive evidence of sexual compatibility.

The following features of self-crosses and intercollection matings were noted: 1) various contact zone morphologies; 2) clamp connection formation on obverse sides of inoculum blocks (evidence of nuclear migration away from the contact zone); 3) hyphal differentiation; and 4) lethal reactions (hyphal lysis in the contact zone).

Monokaryon tester strain isolates (only) from collections 2536 (US), 2315 (Japan), 3810 (USSR), and 2675 (New Zealand) have been deposited with the American Type Culture Collection.

As described previously (Petersen and Bermudes, 1991), bioluminescence was assayed for dikaryon cultures on bread crumb agar using a Pacific Photometrics photomultiplier coupled to an EMI type 9781 A pho-

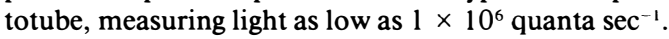
Photometric readings were made at $1,5,14,19$ and 27 da.

\section{RESULTS}

Self-crosses. - All self-crosses, as expected (Macrae, 1937; Petersen and Bermudes, 1991), revealed bifactorial mating systems.

Intercollection matings. - Previous results. Intercompatible intercollection matings between collections from within eastern North America, from within Japan, and between Japanese and North American collections were documented by Petersen and Bermudes (1991).

New Zealand. After selecting tester strains for individual collections from within New Zealand, these were mated against tester strains of collection 2675 , the basidiomata of which were considered typical of the species. These within-New Zealand collections were found to be intercompatible, except for a partial incompatibility between isolates of $2675 \times 2658$ (see Discussion). Contact zone morphology was almost uniformly undifferentiated, showing a tendency toward "flat" morphology. Contact zones of incompatible matings were fully colonized by normal mycelium.

Tester strains from New Zealand collections 2658,2664 , and 2675 were mated with those from Japanese collection 2315 (used by Petersen and Bermudes, 1991). Uniformly compatible matings resulted, with several instances of "barrage" contact zone morphology, and no indication of nuclear migration.

Likewise, tester strains from the same New Zealand collections were mated with those from United States collection 2536 (used by Petersen and Bermudes, 1991). All intercollection matings were uniformly compatible. In several instances, differentiated contact zone morphology was noted, and lethal reactions (see Discussion) were observed in a few matings. No indication of nuclear migration was noted.

USSR. When tester strains from USSR collections 3180,3281 , and 3342 were mated with those from USSR collection 3350, uniformly compatible matings resulted. In several instances clamp connections were formed on the obverse sides of inoculum blocks, indicating nuclear migration away from the contact zone.

Tester strains from all four USSR collections were mated with those from Japanese collection 2315. Uniformly compatible matings resulted except between USSR 3180 and the Japanese collection (see Discussion). Nuclear migration was inferred in several matings.

Likewise, tester strains of the same USSR collections were mated with those from United States collection 2536. Again, uniformly compatible matings were observed. Several instances of significant contact zone morphology were noted, along with several cases of inferred nuclear migration.

Bioluminescence. - No light emission was detected from any culture from New Zealand, USSR, or Japan. Eastern North American cultures were bioluminescent, as reported previously (Petersen and Bermudes, 1991).

Basidiome taste. - Basidiome taste was found to differ across the geographic range. Basidiomata from eastern North America were slowly mildly acrid and caused uncomfortable drying in the mouth (whence the species epithet). Basidiomata from Japan, USSR, and New Zealand, conversely, uniformly produced no sensation in the mouth, but significant constriction and nauseating taste in the throat. While obviously subjective, all collections reported here were tasted by the senior author, so at least the data are consistent.

\section{DISCUSSION}

In self-crosses within collections, mating type $A_{1} B_{1}$ was assigned arbitrarily, usually inclusive of single-spore isolate no. 1 (although this isolate may not have been chosen as a tester strain). Thus, $A_{2} B_{2}$ was dependent on assignment of $A_{1} B_{1}$. If contact zone morphology (usually exhibition of barrage morphology) was clearcut, $A_{1} B_{2}$ could 
be assigned using common $\mathrm{B}$ as a criterion, and $A_{2} B_{1}$ was dependent on it. Because almost all intercollection matings were compatible, adjustment of these assignments was not practical or necessary.

In the intercollection mating between USSR collection 3180 and Japanese collection 2315, however, a common-B mating type gene was apparently shared. This was indicated by the pattern of incompatible matings as well as by the pattern of barrage contact zone morphologies. It was necessary in this case to adjust the assignment of mating types in these two collections to reflect this pattern. Similarly, intercollection matings between New Zealand collections 2658 and 2675 showed a pattern of shared mating alleles. Compatible: incompatible ratio was $3: 1$, with incompatible matings clusterable in the grid. In this case, however, contact zone morphology was not of distinct "flat" (common-A gene) or "barrage" (common-B gene), but undifferentiated, as might be expected in a common-AB pairing. Had 2675 and 2658 shared both an $A$ and a $B$ gene $\left(A_{1} B_{1} / A_{2} B_{2} / A_{1} B_{2} / A_{2} B_{1} \times A_{3} B_{3} / A_{3} B_{1} /\right.$ $A_{1} B_{3} / A_{1} B_{1}$ ), however, a 9:7 ratio of compatible: incompatible matings would result. Nonetheless, contact zone morphology was of no help in determining which mating type gene was shared, so mating types of 2658 were arbitrarily assigned.

These common-gene matings involving collections 2675 and 2658 led to reassignment of mating types for several collections in this study (TABLE I). Because it was not the purpose of the study to investigate the complexity of mating type genes, nor to predict numbers of $\mathrm{A}$ or $\mathrm{B}$ genes, intercollection matings were not performed with all available isolates in all combinations, and mating types were not universally assigned.

Of the USSR collections, no. 3281 was notable for its ability to permit nuclear migration in most matings. This was especially true of isolate 15 which consistently accepted nuclei from its mates, whether from USSR, Japan or North America. Conversely, isolates from USSR collection 3281 were only marginally successful in achieving nuclear migration into their mates. Patterns of nuclear access were assumed to be a function of individual collections rather than isolates within one collection. For example, collection 3350 permitted nuclear migration only rarely (six cases out of 70 matings).

Isolate 11 of United States collection 2536 grew
TABLE I

AsSigned MATING TYPES IN PANELLUS STYPTICUS

\begin{tabular}{|c|c|c|}
\hline Coll. no. ${ }^{a}$ & \multicolumn{2}{|c|}{ Country } \\
\hline \multirow[t]{2}{*}{2536} & \multicolumn{2}{|c|}{ United States } \\
\hline & $\begin{array}{l}7=A_{1} B_{1} \\
1=A_{1} B_{2}\end{array}$ & $\begin{aligned} 2 & =\mathrm{A}_{2} \mathrm{~B}_{2} \\
11 & =\mathrm{A}_{2} \mathrm{~B}_{1}\end{aligned}$ \\
\hline \multirow[t]{2}{*}{2315} & \multicolumn{2}{|c|}{ Japan } \\
\hline & $\begin{aligned} 11 & =A_{3} B_{3} \\
3 & =A_{3} B_{4}\end{aligned}$ & $\begin{array}{l}5=A_{4} B_{4} \\
4=A_{4} B_{3}\end{array}$ \\
\hline \multirow[t]{2}{*}{3810} & \multicolumn{2}{|c|}{ Soviet Union } \\
\hline & $\begin{array}{l}1=A_{5} B_{5} \\
5=A_{6} B_{5}\end{array}$ & $\begin{array}{l}2=A_{6} B_{3} \\
9=A_{5} B_{3}\end{array}$ \\
\hline \multirow[t]{2}{*}{2675} & \multicolumn{2}{|c|}{ New Zealand } \\
\hline & $\begin{aligned} 1 & =A_{7} B_{6} \\
12 & =A_{8} B_{6}\end{aligned}$ & $\begin{aligned} 4 & =A_{8} B_{7} \\
10 & =A_{8} B_{7}\end{aligned}$ \\
\hline \multirow[t]{2}{*}{2658} & \multicolumn{2}{|c|}{ New Zealand } \\
\hline & $\begin{aligned} 1 & =\mathbf{A}_{9} \mathbf{B}_{8} \\
11 & =\mathbf{A}_{9} \mathbf{B}_{9}\end{aligned}$ & $\begin{array}{l}2=A_{10} B_{9} \\
7=A_{10} B_{8}\end{array}$ \\
\hline
\end{tabular}

${ }^{a}$ Corresponds to field number under Materials and Methods.

slowly and compactly when confronted with most USSR isolates, but grew normally in matings with USSR collection 3342 and all New Zealand isolates (restricted growth by this isolate was not reported by Petersen and Bermudes, 1991). Again, such phenomena seem strain-specific, in this case as a response to diffusable substance(s) produced by the mated isolate. Nonetheless, sexual compatibility was not affected, indicating that mating type genes were not overcome by these physiological responses.

United States isolates 2536:2 and 7 caused almost invariable differentiation of contact zone morphology with USSR and New Zealand isolates, while such differentiation was not pronounced in within-New Zealand, within-USSR, New Zealand $\times$ Japan, or USSR $\times$ Japan matings.

Lethal reactions (hyphal lysis within the contact zone) occurred sporadically, being most pronounced in intercollection matings between New Zealand and United States collections. The phenomenon, already noted in self-crosses and intercollection matings of Xeromphalina campanella (Batsch: Fr.) Kuhner \& Maire by Petersen (1990) does not affect compatibility. The lethal reaction may be a function of common mating type alleles but more probably is a strain-specific trait, perhaps related to somatic incompatibility (Rayner, 1991). 
Such a wide distribution of interbreeding populations raises questions concerning gene flow. One theory obviously favors long-distance dispersal of propagules (presumably basidiospores) and would account for the sexual compatibility of such widely scattered isolates. Evidence for such contemporary dispersal, however, is scanty (Redhead, 1989). Moreover, were contemporary intercontinental dispersal common, one would expect a blending within other characters. For example, were intercontinental gene flow common, the marked division between bioluminescent and non-luminescent populations would be unexpected (Macrae, 1942).

If present-day long-distance dispersal is discounted, an opposing theory would require that mechanisms for sexual compatibility remain stable since a time shortly after continental separation when successful transmission of viable propagules ceased. Such allopatric populations, separated for long time periods, might be expected to retain sexual compatibility if withinpopulation mating mechanisms reinforced "status quo ante" systems extant before apparent allopatric separation.

Data on other fungi seem to support widespread distribution of potential interbreeding populations. For example, Pleurotus ostreatus (Jacq.: Fr.) Kummer (Bresinsky et al., 1987), species of Auricularia (Duncan, 1972; Duncan and MacDonald, 1967), and Xeromphalina campanella (Petersen, 1990, and unpubl. data) all seem sexually compatible throughout the North Temperate Zone. Even taxa not often encountered or with significant reproductive barriers [i.e., fruiting on unique substrates, such as Auriscalpium vulgare (L.) S. F. Gray] are sexually compatible over long distances (China and central North America; Petersen and Wu, 1991).

The data presented here are also relevant to principles of evolutionary biology and species concepts. Most contemporary workers agree that the "biological species" concept as circumscribed by Mayr (1942, 1970), Dobzhansky (1970), and others places too much emphasis on real or potential interbreeding (see Donoghue, 1985; Bock, 1986; Templeton, 1989). Under non cladistic species concepts, two phenomena reported here, extrinsic reproductive barriers and uncoupling of breeding from other species-circumscribing traits, seem applicable to contemporary formulation of species concepts.

Some critics of the biological species concept separate consideration of intrinsic $v s$. extrinsic barriers, and genetic $v s$. reproductive barriers (thus arriving at at least four categories). In $P$. stypticus, no genetic barriers have been reported: once representatives of populations are mated, no barrier exists to free gene flow (Macrae, 1942; Petersen and Bermudes, 1991, present paper). Conversely, geographic separation appears to be an effective reproductive barrier, as evidenced by separation of populations exhibiting bioluminescence or not so, and taste differences. Further discussion of this distinction may be found in literature by Bock (1986, and citations within) and Templeton $(1987,1989)$.

Seen from another viewpoint, the ability to interbreed is not inexorably linked to other phenotypic or genotypic traits. Most contemporary exponents of formulation of species concepts direct this conclusion. In the higher fungi, uncoupling of breeding (biological species concept) from phenotypic traits (evolutionary species concept; see papers in Clemençon, 1977, for application to higher fungi; Templeton, 1989) has been implied previously, notably in Auricularia (Duncan, 1972; Duncan and MacDonald, 1967). In P. stypticus, the physiological/biochemical traits of bioluminescence and taste are consistent within, but differ between allopatric populations, and apparently are independent of the ability (or at least the potential) to interbreed.

\section{ACKNOWLEDGMENTS}

RHP: The Hesler Endowment Fund of the Univerity of Tennessee provided financial support for collecting/ culturing in New Zealand and Japan. The Estonian Academy of Sciences supported collecting/culturing in the USSR. Plant Protection Division of DSIR, Auckland, provided transportation while in New Zealand. Personal thanks are offered to Drs. Erast Parmasto, Peter Johnston and Peter Buchanan, and to Takashi Matsushima and Masana Izawa for their good offices and cooperation. DB: Support from an NIEHS National Service Award Grant (ES07043) is gratefully acknowledged. Both authors thank Dr. Rytas Vilgalys for an incisive review and literature suggestions.

\section{LITERATURE CITED}

Bermudes, D., V. L. Gerlach, and K. H. Nealson. 1990. Effects of culture conditions on mycelial growth and luminescence in Panellus stypticus. Mycologia 82: 295-305.

Bock, W. J. 1986. Species concepts, speciation, and macroevolution. Pp. 31-57. In: Modern aspects of species. Eds., K. Iwatsuki, P. H. Raven, and W. J. Bock. Univ. of Tokyo Press, Tokyo. 
$\rightarrow$ Bresinsky, A., M. Fischer, B. Meixner, and W. Paulus. 1987. Speciation in Pleurotus. Mycologia 79: 234 245.

Clemençon, H. (Ed.) 1977. The species concept in Hymenomycetes. J. Cramer, Vaduz, Liechtenstein. 444 pp.

Dobzhansky, T. 1970. Genetics of the evolutionary process. Columbia Univ. Press, New York. 505 pp.

Donoghue, M. J. 1985. A critique of the biological species concept and recommendation for a phylogenetic alternative. Bryologist 88: 172-181.

$\rightarrow$ Duncan, E. G. 1972. Microevolution in Auricularia polytricha. Mycologia 64: 394-404.

$-\rightarrow-$, and J. A. MacDonald. 1967. Micro-evolution in Auricularia auricula. Mycologia 59: 803818.

Macrae, R. 1937. Interfertility phenomena of the American and European form of Panus stipticus (Bull.) Fries. Nature 139: 674.

. 1942. Interfertility studies and inheritance of luminosity in Panus stipticus. Canad. J. Res. C, 20: 411-434.

Mayr, E. 1942. Systematics and the origin of species. Columbia Univ. Press, New York. 334 pp.

- 1970. Populations, species, and evolution. Belknap Press, Cambridge, Massachusetts. 453 pp.

$\rightarrow$ O'Kane, D. J., W. L. Lingle, D. Porter, and J. E. Wampler. 1990a. Localization of bioluminescent tissues during basidiocarp development in Panellus stypticus. Mycologia 82: 595-606. $\longrightarrow,-\rightarrow-, \longrightarrow$, and $\longrightarrow$ 1990b. Spectral analysis of the bioluminescence of Panellus stypticus. Mycologia 82: 607-616.

Petersen, R. H. 1990. Mating systems in the genus Xeromphalina. Mycol. Soc. Amer. Newsletter 41(1): 32. (Abstract)

$\longrightarrow$, and D. Bermudes. 1991. Intercontinental compatibility in Panellus stypticus, with a note on bioluminescence. Persoonia. (In press) , and Q. Wu. 1991. Auriscalpium vulgare: mating system and biological species. Mycosystema. (In press)

Rayner, A. D. M. 1991. The challenge of the individualistic mycelium. Mycologia 83: 48-71.

Redhead, S. A. 1989. A biogeographical overview of the Canadian mushroom flora. Canad. J. Bot. 67: 3003-3062.

Reid, D. A. 1955 . New or interesting records of Australasian basidiomycetes. Kew Bull. 1955(3): 631648.

Segedin, B. P. 1987. An annotated checklist of agarics and boleti recorded from New Zealand. New Zealand J. Bot. 25: 185-215.

Templeton, A. R. 1987. Species and evolution. Evolution 41:233-235.

- 1989. The meaning of species and speciation: a genetic perspective. Pp. 3-27. In: Speciation and its consequences. Eds., D. Otte and J. A. Endler. Sinauer Assoc., Sunderland, Massachusetts.

Accepted for publication November 26, 1991 